\title{
The understanding of the text and images by teenagers with different levels of intelligence with eye tracking using
}

\author{
Oksana V. Zashchirinskaia ${ }^{1}$ and Elena Nikolaeva ${ }^{2, *}$ \\ ${ }^{1}$ St. Petersburg State University, Russian Federation \\ ${ }^{2}$ Herzen State Pedagogical University, Russian Federation
}

\begin{abstract}
The aim of this study was to identify and compare the characteristics of the recognition and understanding of verbal and nonverbal stimuli in the form of a text and drawing images of various degrees of definition applicable to students with mild mental retardation. The objects of the comparative study were graduates of schools with a varying degree of the intelligence decline (F83 - mixed specific disorders of psychological development and F70 - mild mental retardation). 85 subjects were participants. There were $49 \%$ boys and $51 \%$ girls. The study revealed specific features of perception and understanding of the texts and images of different degree of visual complexity by students with mild mental retardation. In the analysis of the visual information, they preferred to focus on the emotional aspect of the content both of the texts and pictures. Students with mild mental retardation demonstrated a lower level of cognitive development and volitional activity when viewing a stimulus of a high degree of visual complexity. A specific feature in the perception and understanding of the texts and images by these students is the lack of cognitive orientation on the procedural side event analysis.
\end{abstract}

Key words: verbal and nonverbal stimuli, mild mental retardation, levels of intelligence, cognitive development, volitional activity.

\section{Introduction}

Currently, the problem of understanding is essential for the development of interdisciplinary research. Its relevance is due to the high importance of the process of understanding, acting as a necessary criterion for successful human functioning (R. Descartes, B. Spinoza, H. Hegel). Understanding is a cognitive phenomenon [1], an analytic-synthetic process that is creative in its nature [2], a mechanism of meaning [3], a prerequisite of communication, joint activities of people, a specific state of consciousness [4], the method of reality cognition [5], an essential human ability and a result of determining procedure productivity interpersonal communications [6], etc.

A number of psychological studies have shown a close relationship between understanding and the basic mental processes, primarily with thinking, memory, speech. Understanding, in this case, is an integral component of knowledge, intellectual activity and human communication. A.A. Brudnyi compared this phenomenon with the "knot" that ties together the knowledge and communication [7].

\footnotetext{
* Corresponding author: klemtina@yandex.ru
} 
Understanding is compared with the translation of a "natural" language to an inner meaning [8]. L.P. Doblaev notes that the analysis of the text of the person poses a specific and focused questions looking for answers [9]. A number of researchers suggest that understanding of the fragments of the text is, first of all, the establishment of a framework of the material [10]. So, from their point of view, to understand the relations presented in the text, the person needs to imagine a real situation in which this relationship might manifest itself. This is the kind of job that a person needs to decide.

According to the representatives of the Würzburg school, in psychology the problem of understanding acts as the relationship between thinking and speech [11]. In particular, K. Dunker reviewed the understanding of how "insight" in which the establishment of relations between the components of the situation. He emphasized, "the deeper understanding of the problem situation, the more it affects the functional solution, the more the decision is a matter of thinking and not the usual replay" [11, p. 59]. From his point of view, a prerequisite for the comprehension is the availability of tasks for the subject, and "functional solution and understanding are not the guides of "psychic" forces or intrusive "ideas", but only express what should be considered as a determining factor of thinking" [11, p. 62]. The author confidently believed that "the comprehension or understanding is the basis of the thinking process" [11, p. 80].

Cognitive processing of visual information is one of the most important and necessary abilities, using of perception and understanding and which are closely interlinked with each other [19-21]. Thus in interdisciplinary studies in cognitive psychology found a small number of experiments, the design of which involves the use of a method of eye tracking.

\section{Material and methods}

The aim of this work was to study the characteristics of recognition and understanding verbal and non-verbal patterns in the text and picturesque presentation of visual stimuli with different degrees of clarity for images. Practical significance of the obtained results is the possibility of developing means of increasing the efficiency of the process of correctional and developing work with normally developing students and with varying degrees of lower intelligence.

The objects of the study were the students with different degree of decrease in intelligence. In accordance with the International classification of diseases and behavioural disorders of $10^{\text {th }}$ review their official clinical diagnoses were F83 - mixed specific disorders of psychological development and F70 - mild mental retardation.

The general hypothesis of the study was that students with mild mental retardation will be extrapolated to the cognitive tasks on everyday situations of social interaction with people. Their basic guidelines for classification of the images and texts of different degree of visual complexity will be due to the introduction of own life experience about the world and social interaction.

To explore the understanding of texts of different visual complexity was used survey method. The design of the study used a method of registration of eye movements (eye tracking) and wavelet image filtering. Mathematical and statistical data processing was carried out using content analysis, a method of multiple comparisons Scheffe and regression analysis.

The total number of participants in the study was 85 people. A preliminary study involved 25 students of 1-4 study years of the Faculty of Psychology of St. Petersburg State University aged 18 to 25 years. In the empirical study, 60 people were interviewed aged 15 to 


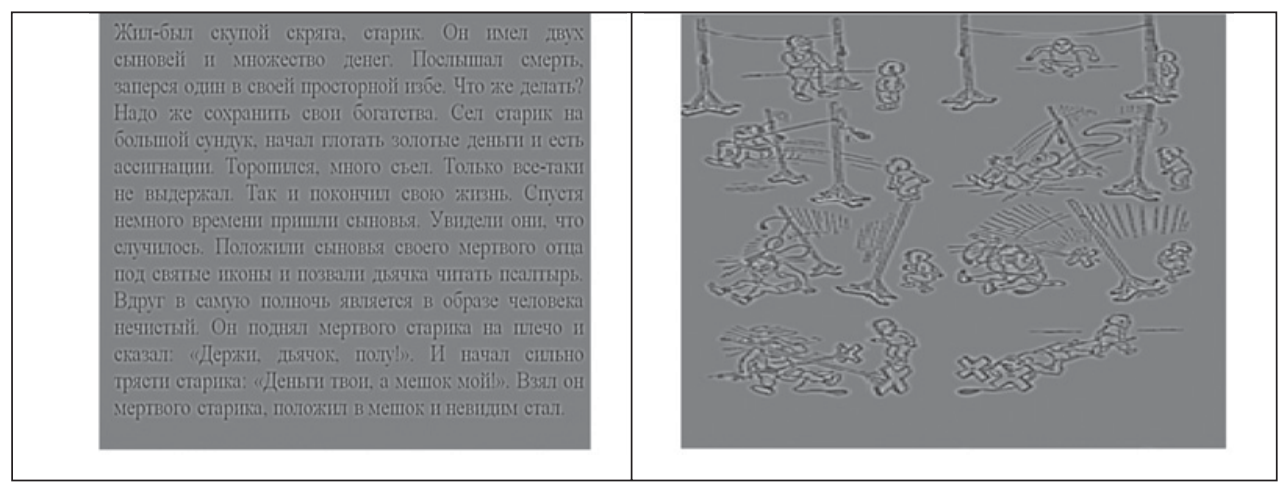

Fig. 1. Samples of the texts and images.

19 years. It included high school students with different level of intellectual development of three educational institutions. Among them there were 20 normally developing students, 20 students with mixed specific developmental disorders and 20 with mild mental retardation. $49 \%$ of respondents were boys and $51 \%$ girls.

The study had several stages. At the initial stage a visual series of story images and texts of different degrees of definition were developed. These incentives were offered for viewing by students in the preliminary study. All images and texts were processed using the method of wavelet filtering, i.e. a method of processing graphic images, by which was secured the blurring of stimuli with variable pitch in the low frequencies. On the monitor screen of the examinee consistently were demonstrated texts and images, in the order from the clearest to most blurred. The used texts were roughly equal in terms of fragments of Russian folk tales in black letters on a gray background (Fig. 1).

Scene images used comics by Bidstrup (Fig. 1). Students were offered incentives 15:7 texts and 8 narrative pictures. After viewing each stimulus, subjects filled out a short questionnaire aimed at the study of understanding what they saw, where they assessed their understanding of the stimulus on a 6-point scale (0-did not understand; 5-well-understood) and how interesting they were placed on the texts and images, as well as briefly expounded the meaning of what he saw. The study was conducted individually.

During presentation of the varieties of texts and comics, we recorded the number and duration of saccades and fixations, time of viewing/reading, the "zone of interests" (a method of registration of eye movements), the subjective assessment of understanding of presented stimuli (method of survey), key concepts observed in the responses of the examinee (the method of content analysis).

In the preliminary study, it was possible to identify at what level of blur the students had difficulties in recognizing materials. The mean rating of understanding of the subject were calculated. It turned out that a significant difficulty in understanding the texts by the students are observed after the 5th stimulus, and in the understanding of the images after 3 . This fact is fundamental for the design of studies for high school students with learning difficulties.

According to the design of research, the next stage was organized for normally developing high school students and their peers with learning difficulties. It was decided to use exactly those stimuli that were well understood by students. Therefore, the stimulus material consisted of 3 texts and 2 of comics. Thus, the procedure of the research has been reduced and has become easier and more accessible for these learners. 


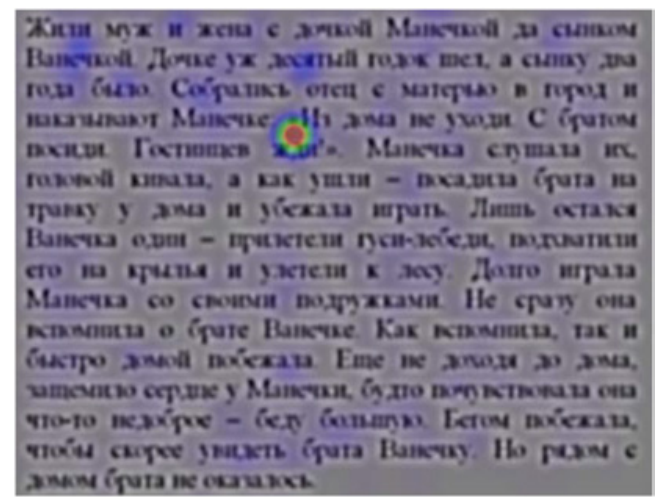

Fig. 2. Indicators of eye fixation among high school students with mental retardation, students in reading texts of 5 th degree of blur.

\section{Results}

It was found that students with mild mental retardation are more focused on the emotional aspect in the analysis of texts and images in the interpretation of nonverbal means of communication between the partners, and this becomes the leading cognitive basis for their understanding of the plot symbols. Interpretation of the peculiarities revealed a trend in the recognition poles of human emotions, because of which there was a specific situation. Teenagers trying to figure out how the main character - a girl - refers to the behaviour of other people, namely, whether there is a danger to this character.

For mentally retarded students important concepts of security events, due to their mental attitudes, emerged in the process of acquiring social experience of interaction with people. It is with significant frequency sounds in their oral and written statements, which are concepts denoting events with different severity: for example, "failed jump" (50\% of those surveyed), "the stretcher for the victim" (20\%), "hospital" (15\%), "help" (15\%), "suffocation" (10\%), "fainted" (5\%), accident (5\%). Thus, the survey of this group brings their own life experience in interpreting the plot, which is consistent with the main hypothesis of the study. In addition, they demonstrate a lower level of cognitive development and volitional activity when viewing a stimulus of a high degree of visual complexity.

For students with mental retardation it is difficult to perceive the text with a high degree of defocus: the number and duration of fixations decrease dramatically.

Students are not trying to stare at individual words to recreate the sense. In this case, text analysis requires the availability and activation of volitional efforts which in mentally retarded students were underdeveloped. This pattern is also evident when looking at the story pictures. The disciples are fixed on the face of the hero, and normally developing peers, consider the figure as a whole.

The study also confirmed the assumption of the low speed of perception of stimuli by students with mild mental retardation: they are statistically significantly different from normally developing peers for the duration of text reading first-and third-degree blur (method of multiple comparisons the Scheffe).

To establish differences in the perception of verbal and nonverbal information the criterion of Wilcoxon ranks iconic has been applied. In this case pairs were compared for assessment of comprehension of the first text and the first comic book, third text and third comic. It turned out that in the group of students with mixed specific disorders of mental development 
Table 1. Parameters of regression analysis (independent variable "group").

\begin{tabular}{|l|l|l|l|}
\hline The dependent variable & $\boldsymbol{R}^{2}$ & $\boldsymbol{\beta}$ & $\boldsymbol{P}$ \\
\hline The number of fixations, comics of the 1st degree of blurring & 0.120 & 0.347 & 0.001 \\
\hline The number of fixations, comics of the 3d degree of blurring & 0.054 & 0.233 & 0.034 \\
\hline The number of fixations, text of the 3d degree of blurring & 0.109 & 0.330 & 0.002 \\
\hline Time of fixations, comics of the 1st degree of blurring & 0.134 & 0.366 & 0.001 \\
\hline Time of fixations, comics of the 3d degree of blurring & 0.140 & 0.374 & 0.000 \\
\hline Time of fixations, text of the 1st degree of blurring & 0.164 & 0.405 & 0.000 \\
\hline Time of fixations, text of the 3d degree of blurring & 0.232 & 0.482 & 0.000 \\
\hline Time of fixations, test of the 5th degree of blurring & 0.078 & 0.280 & 0.010 \\
\hline $\begin{array}{l}\text { Mean length of saccades during perception of the text in the first } \\
\text { degree of blurring }\end{array}$ & 0.116 & -0.341 & 0.002 \\
\hline $\begin{array}{l}\text { Mean length of saccades during perception of the text in the 3d } \\
\text { degree of blurring }\end{array}$ & 0.082 & -0.286 & 0.009 \\
\hline $\begin{array}{l}\text { Mean length of saccades during perception of the text in the 5th } \\
\text { degree of blurring }\end{array}$ & 0.099 & -0.315 & 0.004 \\
\hline $\begin{array}{l}\text { Subjective assessment of understanding comics in the first degree } \\
\text { of blurring }\end{array}$ & 0.171 & -0.414 & 0.000 \\
\hline $\begin{array}{l}\text { Subjective assessment of understanding comics in the 3d degree } \\
\text { of blurring }\end{array}$ & 0.088 & -0.296 & 0.007 \\
\hline $\begin{array}{l}\text { Subjective assessment of understanding comics in the 5th degree } \\
\text { of blurring }\end{array}$ & 0.157 & -0.396 & 0.000 \\
\hline
\end{tabular}

and in the group of children with mild mental retardation statistically significant differences in understanding of texts and comics were not detected.

The initial phase of the regression analysis was aimed at identifying differences between groups. The independent variable was a parameter "Group". It turned out that the groups significantly differ in any objective characteristics: the number of fixations, fixation time and duration of saccades in tasks with pictures and tasks with texts. Significant differences are seen in the table, which presents the regression analysis (Table 1) and qualitative data analysis in all groups (Table 2).

Table 2 shows how the number of fixations increases gradually, and their number for pupils with mental retardation is twice higher than for the students. A similar ratio is observed for the time of fixations on the picture. However, for the duration of the saccade students differ from other subjects, whereas no differences were found between pupils. This may indicate a lack of willingness to look at the detail in all groups.

Among all groups there is a decline in accuracy of perception of the complication of material in a situation of perception of comics in the third degree of blurring with the exception of normally developing students. They have not revealed deterioration in understanding images. The scatter of data was so significant that the average value of the number of fixations did not differ. Children with lower intelligence have a tendency of increase in number of commits.

As in the previous situation, the difference between the groups is directed towards lengthening the fixation time and children with mental retardation commit twice more than the students. In each group, comparative to the previous experimental situation, when a clear picture was presented, there is a reduction of time of gaze fixation. Therefore, an attemption to understand the complex material is not by focusing on a single element, but by increasing the space of observation. 
Table 2. A comparative analysis of the physiological parameters scores of subjects of different groups during the presentation of paintings.

\begin{tabular}{|l|r|c|c|c|}
\hline \multirow{2}{*}{ Parameters } & \multicolumn{4}{|c|}{ Subjects } \\
\cline { 2 - 5 } & students & pupils & $\begin{array}{l}\text { pupils with mixed } \\
\text { specific disorders } \\
\text { development }\end{array}$ & $\begin{array}{l}\text { pupils with } \\
\text { mildmental } \\
\text { retardation }\end{array}$ \\
\hline $\begin{array}{l}\text { Comic 1, the number of } \\
\text { fixations }\end{array}$ & $89.9 \pm 49.4$ & $112.8 \pm 77.0$ & $135.2 \pm 80.1$ & $167.3 \pm 110.0$ \\
\hline $\begin{array}{l}\text { Comic 1, the time of } \\
\text { fixations (s) }\end{array}$ & $31.2 \pm 16.3$ & $47.2 \pm 34.2$ & $52.4 \pm 29.8$ & $67.2 \pm 50.6$ \\
\hline $\begin{array}{l}\text { Comic 1, the mean } \\
\text { length of saccades (ms) }\end{array}$ & $170.8 \pm 17.0$ & $191.1 \pm 24.2$ & $190.5 \pm 30.7$ & $186.0 \pm 31.3$ \\
\hline $\begin{array}{l}\text { Comic 3, the number of } \\
\text { fixations }\end{array}$ & $75.9 \pm 44.6$ & $64.5 \pm 28.5$ & $89.7 \pm 68.9$ & $115.4 \pm 87.8$ \\
\hline $\begin{array}{l}\text { Comic 3, the time of } \\
\text { fixations (s) }\end{array}$ & $26.5 \pm 22.4$ & $29.1 \pm 1.5$ & $46.8 \pm 31.2$ & $51.5 \pm 33.5$ \\
\hline $\begin{array}{l}\text { Comic 3, the mean } \\
\text { length of saccades }\end{array}$ & $180.2 \pm 22.3$ & $203.8 \pm 23.4$ & $207.5 \pm 45.8$ & $190.5 \pm 31.0$ \\
\hline
\end{tabular}

The average duration of a saccade does not increase with increasing group numbers, that is, as the complexity of the diagnosis. Mentally retarded teenagers do not try to increase understanding through the context and get a holistic information about the plot.

In general, in understanding of the text presented with a low degree of blur, there is a large variety of reactions of the examinee. When reading they all do a larger number of fixation s than when looking at paintings. However, a large standard deviation does not reveal any patterns. The dispersion of data significantly less in normally developing students, then in other children which can be explained by the specificity of schooling, which requires constant attention to the text.

Pupils and students fixed significantly shorter on the text than teenagers with different degree of intelligence decrease. This leads to a significant influence of the independent variable a "group" for this parameter (Table 2). The saccade's duration in normal text presentation do not differ in different subjects.

The complication of the text perception as of the figure, does not increase the number of fixations, which, however, decreases relative to this indicator in the group in simpler terms, but from group to group, the number of fixations increases. The length of saccades in norm increases slightly, while reducing intelligence, on the contrary, decreases. Adolescents with mild mental retardation stare at the text without trying to map read parts with the previous information in the process of reading the presented fragments, resulting in a negative impact of the independent variable "group" on the indicator "number of fixations" (Table 2).

\section{Conclusions}

1. On the basis of preliminary studies the specific perception and understanding of texts and images with different degrees of visual complexity was not found statistically significant difference in the understanding of pictures and texts in different levels of clarity.

2. For pupils with learning difficulties the basic criteria for differentiation of the complexity of visual stimuli were found out. It was shown that the significant difficulties in understanding the texts by the students were observed after $5^{\text {th }}$ stimulus. While browsing the comic book, understanding is reduced after $3 \mathrm{~d}$ stimulus. Given the characteristics of pupils with learning difficulties we needed to reduce the research procedure and its 
complexity. Therefore, in the empirical study, the stimuli used 2 comics ( 1 and 3 degrees of blur) and 3 texts (1, 3, 5 degrees of blurring).

3. The specific features of the perception and understanding of the texts and images of different degree of visual complexity by pupils with mild mental retardation compared to their peers with specific disorders of mental development were identified. Both studied groups bring their own life experience in interpreting the plot.

4. Students with mild mental retardation are more focused on the emotional aspect in the analysis of texts and images, on notions of security events. They demonstrate a lower level of cognitive development and volitional activity when viewing a stimulus of high degree of visual complexity. Cognitive landmarks of peers with mixed specific disorders of psychological development to a greater extent associated with the identification of the main characters of the story and their actions, the concept of security of heroes are not fundamental in interpretation of the story by pupils.

5. The specificity of the perception and understanding of texts and images with different degrees of visual complexity by pupils with mild mental retardation compared to their normally developing peers were shown. Pupils with mild mental retardation paid attention to the emotive component. Normally developing peers focused on the identification of key figures from the point of view of what is happening with them changes, i.e. for them, the important procedural aspects of the analysis of events.

Project "Physiological and neurolinguistic aspects of the recognition process of verbal and non-verbal patterns" funded by the Russian Scientific Found 14-18-02135.

\section{References}

[1] P. Solso, Kognitive psychology (SPb: Piter, 2006)

[2] N.A. Menchinskaya, Problems of education and child psychic development, M.: MPSI (MODEK, Voronej, 2004)

[3] M.M. Bachtin, Estaetic of verbal creativity (M: Iskusstvo, 1986)

[4] V.V. Znakov, Understanding in thinking, communication, and human being been (M: IPAN, 2007)

[5] V.P. Zinchenko, Psychological Sci. Educ. 3, 42-52

[6] D. Keltner, D.J. Haidt, Cognition and Emotion 13(5), 505 (1999)

[7] A.A. Brudny, Voprosi Psychologii 10, 109 (1975)

[8] O.A. Belobrikina, Smalta 1, 9 (2016)

[9] L.P. Doblaev, The semantic structure of the educational text and the problem of its understanding (M.: Pedagogics, 1982)

[10] D.E. Rumelhart, Basic processes in reading: Perceptions and Comprehension, edited by D.L. Laberge, S.J. Samuels (Language Arts \& Disciplines, Erlbaum, 1977)

[11] Psychology of thinking (M.: Progress, 1965)

[12] A.M. Lamminpia, O.V. Zaschirinskaya, Yu.E. Shelepin, Petersburg Psychological J. 6, $16(2014)$

[13] A.M. Lamminpia, O.V. Zaschirinskaya, Yu.E. Shelepin, Hum. Physiol. 41(2), 130 (2015) 